\title{
Type D Personality, Temperament, and Mental Health in Military Personnel Awaiting Deployment
}

\author{
Paula M. C. Mommersteeg • Johan Denollet • \\ Annemieke Kavelaars • Elbert Geuze • Eric Vermetten • \\ Cobi J. Heijnen
}

Published online: 15 May 2010

(C) The Author(s) 2010. This article is published with open access at Springerlink.com

\begin{abstract}
Background The Type D (distressed) personality refers to a general propensity to psychological distress defined by the combination of negative affectivity and social inhibition. Type D personality predicts poor mental and physical health in cardiac patients, but it has been argued that its assessment is affected by the state of illness. Therefore, validation of the Type $\mathrm{D}$ construct in healthy adults remains essential.

Purpose The objectives of this study were (1) to validate Type D personality against temperament and character dimensions in young, healthy adults and (2) to investigate the association between Type D personality and predeployment mental health.

Method Type D personality, temperament, and questionnaires on mental health were filled out by 86 healthy male Dutch military personnel before UN deployment to Afghanistan.

Results Type D personality was present in $16 \%$ of healthy military personnel before deployment. The Type D compo-
\end{abstract}

P. M. C. Mommersteeg · J. Denollet

CoRPS, Center of Research on Psychology in Somatic diseases,

Tilburg University,

Tilburg, The Netherlands

P. M. C. Mommersteeg · A. Kavelaars · C. J. Heijnen

Laboratory for Psychoneuroimmunology,

University Medical Center Utrecht,

Utrecht, The Netherlands

E. Geuze $\cdot$ E. Vermetten

Ministry of Defense, Military Mental Health-Research Centre,

Utrecht, The Netherlands

P. M. C. Mommersteeg $(\varangle)$

CoRPS, Department of Medical Psychology, Tilburg University,

P.O. Box 90153, 5000 LE Tilburg, The Netherlands

e-mail: P.M.C.Mommersteeg@uvt.nl nents social inhibition $(\alpha=0.89)$ and negative affectivity $(\alpha=$ 0.85 ) correlated positively with harm avoidant temperament $(r=0.66$ and 0.46$)$ and negatively with self-directed character $(r=-0.33$ and -0.57$)$. In addition, these four traits loaded on the same broad personality dimension. Military men with a Type D personality not only reported significantly less selfdirectedness and more harm avoidance as compared to nonType D men $(p<0.001)$ but also more symptoms of PTSD, general emotional distress, and hostility (all $p<0.012$ ).

Conclusions Type D personality was associated with harm avoidance, low self-directedness, and increased symptoms of PTSD and hostility in men awaiting deployment. This association was not caused by any somatic confounding in these young, healthy men.

Keywords Type D · Mental health · Pre-deployment . Validation studies $\cdot$ Temperament $\cdot$ Risk factors

\section{Introduction}

Type D personality refers to the combination of two traits: negative affectivity (the tendency to experience feelings of dysphoria, anxious apprehension, and irritability) and social inhibition (the tendency to feel uncomfortable and inhibited in social interactions) [1]. A growing body of evidence shows Type D personality as a risk factor for poor prognosis in patients with cardiovascular disease, independent of traditional biomedical risk factors [2]. In addition, in patients who survived a myocardial infarction, Type D personality was found to predict post-traumatic stress disorder (PTSD) above and beyond other risk factors such as age, gender, neuroticism, and extroversion [3]. It has been suggested that the presence of Type D may be affected by the state of illness, as "the knowledge of having a 
serious illness affects people's moods and confidence in social interactions" [4]. In this respect, one could argue that Type D is disease state specific rather than a stable trait. Therefore, it is important to validate the Type D personality construct in a young, healthy group of persons who are free from underlying somatic disease.

Type D personality has a prevalence of $19 \%$ in the general population [1]. It has been validated against the "big five" NEO-FFI personality model [1,5], which was originally developed to account for adult individual differences in the general population. Negative affectivity showed a high positive correlation with neuroticism, and negative with extraversion, conscientiousness, and agreeableness, whereas social inhibition was negatively correlated to extraversion and conscientiousness and positively with neuroticism [5]. However, information on the temperamental characteristics of the Type D construct is lacking. Cloninger's temperament and character inventory (TCI) was designed to assess novelty seeking, harm avoidance, reward dependence, and persistence. These four temperament dimensions are assumed to be inheritable stable traits which have a psychobiological basis. The three character dimensions self-directedness, cooperativeness, and selftranscendence provide a more complete description of individual differences [6]. The TCI and the NEO-FFI domains are interrelated [7]; neuroticism is correlated with harm avoidance and negatively with self-directedness, and extraversion is correlated with reward dependence and novelty seeking and negatively with harm avoidance. Based on previous studies $[1,5,7]$, we hypothesized that the Type D subscale negative affect (related to neuroticism) is positively correlated with harm avoidance and negatively with self-directedness and that social inhibition (related to extraversion) is positively correlated with harm avoidance and negatively with novelty seeking and reward dependence.

The study population of healthy respondents in the present study was comprised of military personnel before deployment to Afghanistan. Military personnel are at risk for exposure to traumatic events during deployment on a peacekeeping or combat mission. Deployment to a war zone is characterized by chronic hyperarousal on which traumatic events can be superimposed. Being exposed to or witnessing of traumatic events is the major determinant for the development of mental health complaints, of which PTSD is the most well known [8-15]. Pre-existing personality traits have also been associated with an increased risk for the development of PTSD. Predeployment negativism and psychopathology, but not shyness or extraversion, have predicted post-deployment PTSD [16]. Elevated levels of neuroticism, a harm avoidant coping style, hostility, and low self-efficacy have all been associated with PTSD [13, 17-19]. These personality characteristics may reflect a general vulnerability for developing PTSD. In this respect, we hypothesized that Type D personality is related to pre-deployment reported mental health problems.

The goal of the present study was twofold: (1) to validate Type $\mathrm{D}$ personality against temperament and character dimensions in a group of young, healthy adults and (2) to investigate the association between Type D personality and pre-deployment mental health problems.

\section{Methods}

Participants

Ninety-two Dutch military persons (86 men, six women; mean age 28.5 years, $\mathrm{SD}=8.7$, range $18-53$, median 25 years) were included in a pre-deployment training period in October 2006 before being sent on a 4-month UN deployment to the province of Uruzgan, Afghanistan. Study participation was on a voluntary basis. Questionnaires were filled out during a morning session. All participants provided informed consent, and the study was approved by the medical ethical committee of the University Medical Center Utrecht.

\section{Measures}

\section{Type D Personality}

The DS14 was used to evaluate negative affectivity (NA) and social inhibition (SI). The 14-item scale was divided in two groups of seven items to assess NA and SI. The responses were evaluated on a five-point Likert scale, ranging from 0 (false) to 4 (true), the score range is $0-28$. Type D personality type was defined according to previously set cutoff scores $(\mathrm{NA} \geq 10$ and $\mathrm{SI} \geq 10)$.

\section{Temperament and Character}

The short form of the temperament and character inventory (TCI-105) [20] is based on Cloninger's psychobiological model of temperament and character [6]. It consists of 105 true or false items, divided into four 15-item temperament scales (novelty seeking, harm avoidance, reward dependence, and persistence) and three 15-item character scales (self-directedness, cooperativeness, and self-transcendence). The mean \pm standard deviation of the general Dutch population is given in Table 2 [21].

\section{Mental Health}

PTSD The self-rating inventory for post-traumatic stress disorder [22] was used to assess self-reported PTSD 
symptoms. This scale includes 22 items based on DSM-IV criteria for PTSD, with subscales intrusion, avoidance, and hyperarousal and a total score. The items are rated on a four-point Likert scale, ranging from $1=$ not at all, to $4=$ extremely. Cronbach's alpha was 0.70 for the intrusion subscale (possible range 6-24), avoidance $=0.79$ (possible range 9-36), hyperarousal $=0.76$ (possible range $7-28$ ), and the total score $=0.88$ (possible range 22-88). Cutoff criteria for self-reported PTSD have been suggested [22, 23], though a PTSD diagnosis should be validated based on a clinical interview as well [8].

General distress and hostility General complaints were measured with the Symptom Check List 90 (SCL90) [24]. The scale consists of 90 items on a five-point Likert scale, ranging from 1 (not at all) to 5 (very much). The total score indicates the general level of distress (Cronbach's alpha= $0.95)$; the average distress score for the general population $(n=2,368)$ is $118.3(\mathrm{SD}=32.4)$ [25]. In the present study, the lowest value of the scale was set to 0 instead of 90 .

The Cook-Medley Hostility Scale was used to measure hostility (Cronbach's alpha $=0.83)$ [26]. Since the subscales cynicism $(\alpha=0.73)$, aggressive responding $(\alpha=0.54)$, and hostile affect $(\alpha=0.51)$ as suggested by Barefoot et al. [26] had insufficient internal validity, the total score based on 50 true/false items was used in the present study (range 0-50). As a reference, the total score in the study of Suarez et al. in healthy nonsmoking American males $(n=90)$ was 19.1 $(\mathrm{SD}=7.7)$ [27].

\section{Statistical Analysis}

Principal component analysis with varimax rotation was used to evaluate the structural validity of the DS14. A secondary factor analysis was used for the subscales of the DS14; NA and SI, together with the subscales of the TCI105; NS, harm avoidance, reward dependence, persistence, self-directedness, cooperativeness, and self-transcendence. The variance of factor loadings were maximized and displayed in the rotated component matrix by making high loadings higher and low ones lower. This facilitates the interpretation of a factor by making unambiguous the variables that correlate with it [28]. Pearson correlation (one-tailed) was used to correlate the DS14 with the TCI105 scales. The internal consistency was assessed with Cronbach's $\alpha$ and the mean inter-item correlation (MIIC, the mean of all item correlations). Correlations between the DS14 subscales with the other questionnaires were done with either Pearson correlation (one-tailed) for the hostility score, Spearman's rho (one-tailed) for the general distress score, due to skewed data, and Kendall's Tau for the PTSD subscales, as they were left censored. Mean scores in TCI-
105 subscales and hostility stratified by Type D personality were analyzed with a one-way ANOVA. Due to a skewed distribution of the SCL90 total score and censored PTSD data (most people report no complaints), stratification by Type D personality was done with a Mann-Whitney $U$ test. Comparisons of norm scores with the mean and SD in this study were done with a Student's $t$ test. A $p$ value of 0.05 was considered significant. All analyses were performed with SPSS 11.0 and 17.0 for Windows (SPSS Inc, Chicago, IL, USA).

\section{Results}

Type D Assessment in Military Personnel

The prevalence of Type D personality was $15 \%$ (14/92); none of the six women in this group met the Type D criteria, and they were excluded from further analysis. The mean negative affect score was $6.53(\mathrm{SD}=4.6)$, which is not different from the mean NA score of the general population $(N=1,235$, mean $=6.3, \mathrm{SD}=5.3, t$ value $=0.44, p=0.67)$ [1]. The studied group reported less social inhibition (mean= $8.55, \mathrm{SD}=5.9$ ), compared to the general population (mean= $10.2, \mathrm{SD}=6.6, t$ value $=-2.26, p=0.012$ ).

The test for the validity of the DS14 confirmed the twofactor structure. The assumptions of the Kaiser-MeyerOlkin measure of sampling adequacy $(0.85 ; \mathrm{df}=91, p=$ $0.005)[1]$ and the Bartlett's test of sphericity $(p<.001)$ were met. The scree plot showed the two-factor structure with a total of $59.7 \%$ explained variance, $30.8 \%$ for NA, and $28.8 \%$ for SI. All of the DS14 items loaded on their corresponding trait factor (Table 1). The internal consistency of the scale was good (Table 1).

Type D persons were not different in age, BMI, smoking, alcohol use, previous deployment, marital status, and medication use compared to non-Type D persons. There were no Type D participants in the "higher educated" category, and more Type Ds in the lower educated category (Table 2).

\section{Type D, Temperament, and Character}

There was a significant correlation between the DS14 and the TCI subscales (Table 3). The SI scale correlated $r=0.66$ (95\% CI $=0.52-0.76)$ with harm avoidance, indicating $44 \%$ shared variance, whereas NA had a negative correlation with self-directedness $(r=-0.57,95 \% \mathrm{CI}=0.41-0.70)$, indicating $32 \%$ shared variance. Smaller, but significant, correlations were observed for negative affect and social inhibition with harm avoidance, persistence, and cooperativeness.

Secondary factor analysis showed a five-factor solution $(\mathrm{KMO}$ value $=0.696$, Bartlett's test of sphericity $p<.001)$. 
Table 1 Structural validity and internal consistency of the DS14 and its subscales

\begin{tabular}{|c|c|c|c|}
\hline \multirow[t]{2}{*}{ DS14 items } & \multicolumn{2}{|c|}{ Principal component analysis } & \multirow[t]{2}{*}{ Internal consistency ${ }^{\mathrm{a}}$} \\
\hline & Factor I & Factor II & \\
\hline \multicolumn{4}{|l|}{ Negative affectivity } \\
\hline \# 2 I often make a fuss about unimportant things & 0.48 & 0.07 & .39 \\
\hline \# 4 I often feel unhappy & 0.64 & 0.17 & .52 \\
\hline \# 5 I am often irritated & 0.72 & 0.13 & .64 \\
\hline \# 7 I take a gloomy view of things & 0.81 & 0.14 & .74 \\
\hline \# 9 I am often in a bad mood & 0.77 & 0.20 & .67 \\
\hline \# 12 I often find myself worrying about something & 0.70 & 0.11 & .58 \\
\hline \multirow[t]{3}{*}{ \# 13 I am often down in the dumps } & 0.81 & 0.16 & .73 \\
\hline & & Eigenvalue $\mathrm{I}^{\mathrm{c}}=4.3$ & $\alpha=0.85$ \\
\hline & & & $\mathrm{MIIC}=0.45$ \\
\hline \multicolumn{4}{|l|}{ Social inhibition } \\
\hline \# 1 I make contact easily when I meet people ${ }^{b}$ & 0.03 & -0.88 & .76 \\
\hline \# 3 I often talk to strangers ${ }^{\mathrm{b}}$ & 0.18 & -0.77 & .54 \\
\hline \# 6 I often feel inhibited in social interactions & 0.56 & 0.58 & .63 \\
\hline \# 8 I find it hard to start a conversation & 0.23 & 0.70 & .64 \\
\hline \# 10 I am a closed kind of person & 0.32 & 0.76 & .75 \\
\hline \# 11 I would rather keep other people at a distance & 0.34 & 0.74 & .74 \\
\hline \multirow[t]{3}{*}{ \# 14 When socializing, I don't find the right things to talk about } & 0.36 & 0.75 & .75 \\
\hline & & Eigenvalue $\mathrm{II}^{\mathrm{c}}=4.0$ & $\alpha=0.89$ \\
\hline & & & $\mathrm{MIIC}^{\mathrm{d}}=0.54$ \\
\hline
\end{tabular}

\footnotetext{
${ }^{a}$ Corrected Item-Total Correlation

${ }^{\mathrm{b}}$ Reverse keyed

${ }^{c}$ Rotated eigenvalue of the factor

${ }^{\mathrm{d}}$ Mean inter-item correlation
}

The model explained $72.7 \%$ variance. The SI and NA subscales loaded on one factor together with harm avoidance and (low) self-directedness. The remaining subscales of the TCI fitted in separate factors.

Persons with a Type D personality reported significantly lower levels of self-directedness and higher levels of harmavoidance (Table 4). A lower level of persistence in Type D persons was not significant after Bonferroni correction.

Compared to norm scores of the general population (21, Table 4 first column), non-Type D military personnel were more novelty seeking, less harm avoidant, less reward dependent, more persistent and self-directed, and showed less cooperativeness and self-transcendence. Type D military persons were not different from the general population with two exceptions: they showed significantly lower scores for reward dependence and cooperativeness (both $p=.003$ ).

Type D and Mental Health

Type D personality was associated with significant higher levels of self-reported PTSD symptoms; intrusion, avoid- ance, and hyperarousal (Fig. 1). Negative affectivity had a positive correlation with the self-reported PTSD scales intrusion $(r=0.25, p=.002)$, avoidance $(r=0.35, p<.001)$, and hyperarousal $(r=0.39, p<.001)$. Social Inhibition correlated positive with the PTSD scale avoidance $(r=$ $0.31, p<.001$ ).

Regarding general mental health, Type D personality was associated with a significantly higher SCL-90 general distress score and a higher hostility score (Fig. 2). The subscale NA showed a significant positive correlation with general distress $(r=0.49, p<.001)$ and hostility $(r=0.43$, $p<.001)$. A significant correlation was also found between the SI subscale with general distress $(r=0.24, p=.013)$, and hostility $(r=0.23, p=.017)$.

In addition, a post hoc multivariate regression analysis was done to control for the observed differences in education level (low, medium, high). Type D remained significantly related to increased mental health scores of PTSD symptoms (intrusion, avoidance, and hyperarousal, $F$ $(1,84)=7.3,8.0$, and $7.5, p=.008, .006$, and .008, respectively), general distress and hostility $(F(1,84)=19.3$, and 5.6, $p<.001$, and .20, respectively). 
Table 2 Demographic variables of non-Type D and Type D military personnel
${ }^{\mathrm{a}} F$ value for age and BMI, other $\chi^{2} . * * p<.01$

${ }^{\mathrm{b}}$ Senior/Field Officers and Junior/ Company grade

${ }^{\mathrm{c}}$ Sergeant and Corporal

${ }^{\mathrm{d}}$ Private

\begin{tabular}{|c|c|c|c|}
\hline & $\begin{array}{l}\text { Non-Type D } \\
n=72 \\
\%(\mathrm{n})\end{array}$ & $\begin{array}{l}\text { Type D } \\
n=14 \\
\%(\mathrm{n})\end{array}$ & Test value $^{\mathrm{a}}$ \\
\hline Age $($ mean $\pm \mathrm{SD})$ & $29.0 \pm 8.7$ & $27.4 \pm 10.4$ & 0.38 \\
\hline $\mathrm{BMI}($ mean $\pm \mathrm{SD})$ & $24.9 \pm 2.7$ & $24.8 \pm 2.4$ & 0.01 \\
\hline Smoking [yes] & $48(35)$ & $57(8)$ & 0.34 \\
\hline Alcohol use [ $>5$ units/week] & $44(32)$ & $28(4)$ & 1.21 \\
\hline \multicolumn{4}{|l|}{ Education } \\
\hline Lower & $31(22)$ & $79(11)$ & \\
\hline Middle & $56(40)$ & $21(3)$ & $11.72 * *$ \\
\hline Higher & $10(14)$ & $0(0)$ & \\
\hline \multicolumn{4}{|l|}{ Military rank } \\
\hline Officers $^{\mathrm{b}}$ & $22(16)$ & $7(1)$ & \\
\hline Non-commissioned officers ${ }^{c}$ & $35(25)$ & $36(5)$ & 1.87 \\
\hline Other enlisted personnel ${ }^{\mathrm{d}}$ & $43(31)$ & $57(8)$ & \\
\hline Previous mission [yes] & $50(36)$ & $50(7)$ & 0.00 \\
\hline \multicolumn{4}{|l|}{ Marital status } \\
\hline Married/cohabiting & $47(34)$ & $29(4)$ & \\
\hline Long-term relationship & $24(17)$ & $43(6)$ & 2.55 \\
\hline Single/divorced & $29(21)$ & $29(4)$ & \\
\hline Medication use [yes] & $8(6)$ & $7(1)$ & 0.02 \\
\hline
\end{tabular}

\section{Discussion}

The present findings indicate that Type $\mathrm{D}$ personality is present in a subgroup of healthy military personnel before deployment. The Type D subgroup has elevated scores on the temperament and character scales harm avoidance and self-directedness and shows higher levels of PTSD symptoms, general distress, and hostility compared to the non-Type D group.

The overall low scores on the temperament and character subscales imply that military personnel is tougher and more resilient than the general population, which would make them more suitable for their work and probably somewhat less prone to health-related complaints as PTSD. The study by Engelhard and colleagues points in that direction, showing that Dutch military personnel after a 4-month deployment to Iraq had a rather low mean prevalence (3$4 \%$ ) of clinically diagnosed PTSD [8]. The group of Sareen et al. showed that a military group which had been deployed on a peacekeeping mission but had not been exposed to combat or atrocities were at lower risk for certain mental disorders [14]. Hotopf et al. compared UK armed forces either deployed to the Iraq war or not but did not find significantly worse health outcomes in the deployed group compared to the non-deployed group [29]. However, the present findings may imply that a subgroup of deployed soldiers are at increased risk for mental health problems, i.e., those with Type D personality.

The Type $\mathrm{D}$ subscales negative affect and social inhibition showed good internal consistency. Also, the constructs of negative affect and social inhibition were
Table 3 Construct validity of the DS14 subscales

\begin{tabular}{|c|c|c|c|c|c|c|c|}
\hline & & \multicolumn{2}{|c|}{ Pearson correlation $\mathrm{r}$} & \multicolumn{4}{|c|}{ Rotated component matrix } \\
\hline & & SI & NA & 1 & 2 & 3 & 4 \\
\hline DS14 & Social inhibition & & & 0.79 & 0.17 & -0.27 & -0.16 \\
\hline DS14 & Negative affectivity & $0.48 * * *$ & & 0.76 & -0.14 & -0.08 & 0.26 \\
\hline TCI-105 & Novelty seeking & -0.16 & 0.00 & -0.58 & -0.79 & 0.26 & -0.07 \\
\hline TCI-105 & Harm avoidance & $0.66^{* * *}$ & $0.46^{* * *}$ & 0.84 & 0.02 & -0.17 & -0.10 \\
\hline TCI-105 & Reward dependence & $-0.39 * * *$ & $-0.30 * *$ & -0.26 & 0.15 & 0.73 & 0.30 \\
\hline TCI-105 & Persistence & $-0.28 * *$ & -0.17 & -0.14 & -0.12 & 0.73 & -0.27 \\
\hline TCI-105 & Self-directedness & $-0.33 * *$ & $-0.57 * * *$ & -0.66 & 0.35 & 0.07 & -0.40 \\
\hline TCI-105 & Cooperativeness & -0.10 & $-0.25^{*}$ & -0.14 & 0.77 & 0.37 & -0.12 \\
\hline TCI-105 & Self-transcendence & -0.03 & $0.23^{*}$ & 0.04 & -0.01 & -0.02 & 0.91 \\
\hline
\end{tabular}


Table 4 Temperament and character traits as a function of Type D personality
${ }^{a}$ Duijsens et al. 1999 [21], $N=227$

${ }^{\mathrm{b}}$ Non-Type D versus Type D comparison

$* * p<.001, * p<.05$

\begin{tabular}{lcccc}
\hline & $\begin{array}{l}\text { Norm score } \\
\text { Mean (SD) }\end{array}$ & $\begin{array}{l}\text { Non-Type D } \\
\text { Mean (SD) }\end{array}$ & $\begin{array}{l}\text { Type D } \\
\text { Mean (SD) }\end{array}$ & $F^{\mathrm{b}}$ \\
\hline TCI-105 & & & & \\
Novelty seeking & $6.5(3.2)$ & $7.82(2.65)$ & $7.29(3.20)$ & 0.45 \\
Harm avoidance & $6.5(4.0)$ & $3.21(2.64)$ & $6.64(4.01)$ & $16.5^{* *}$ \\
Reward dependence & $9.4(3.1)$ & $7.92(2.69)$ & $6.71(2.73)$ & 2.33 \\
Persistence & $8.8(3.0)$ & $10.36(2.53)$ & $8.57(4.16)$ & $4.64^{*}$ \\
Self-directedness & $11.9(3.2)$ & $13.74(1.80)$ & $11.43(2.31)$ & $17.39^{* *}$ \\
Cooperativeness & $13.1(2.5)$ & $11.50(3.29)$ & $9.93(3.29)$ & 2.67 \\
Self-transcendence & $5.1(4.0)$ & $2.61(2.14)$ & $3.93(4.38)$ & 2.97 \\
\hline
\end{tabular}

well validated. The findings add to the knowledge that Type $\mathrm{D}$ is present in a healthy group of adults, without disease complaints. Our studied group showed less social inhibition compared to the general population, and the Type D prevalence was somewhat lower than in the general population, i.e., $16 \%$ vs. $19 \%$, respectively.

There were significant correlations between SI and NA with the temperament and character scales. Social inhibition was strongly correlated with harm avoidance and to some extent correlated negatively with reward dependence, persistence, and self-directedness, but not with novelty seeking as we had hypothesized. NA was negatively correlated with self-directedness and positively correlated with harm avoidance and to some extent with reward dependence, persistence, and cooperativeness. These findings were confirmed by factor analysis; NA, SI, harm avoidance, and self-directedness grouped into a single factor, probably due to the overlap between the SI and NA scale.

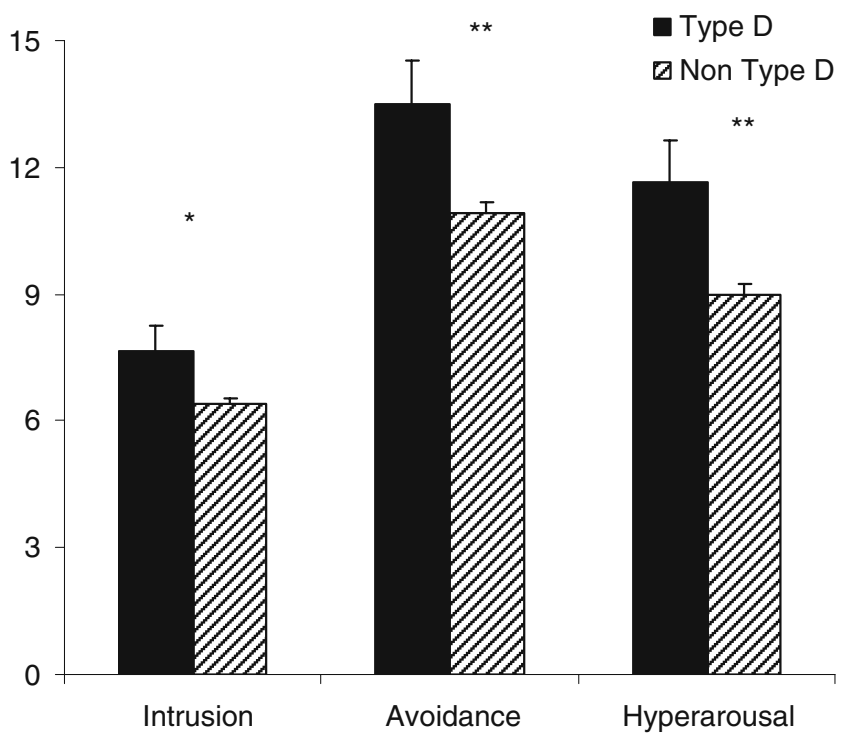

Fig. 1 Differences in self-reported PTSD symptoms for Type D (black) versus non-Type D (striped) military personnel. PTSD subscales intrusion, avoidance, and hypersarousal. ${ }^{*} p<.05, * * p<.01$. Mean + SEM are shown
Despite low to normal scores of the military group on harm avoidance compared to the general population, a higher SI score was related to an increase in harm avoidance. Harm avoidance involves a heritable bias in the inhibition of behavior and is characterized by fear of uncertainty, shyness with strangers, pessimistic worry, and fatigability $[6,30]$. SI refers to "the tendency to inhibit emotions/behavior in social interactions" [1], which matches the harm avoidance construct on a conceptual level.

Non-Type D persons reported overall high levels of selfdirectedness, whereas Type D persons were not different from the general population. Persons high in selfdirectedness are said to be responsible, self-confident, realistic, and effective in their actions [6, 30]. Persons with high negative affect show dysphoria, worry, and irritability [1]. The relation with self-directedness shows that it is not just a negative perception of events that forms the basis of this construct, but those persons are also less capable of adapting their behavior to achieve goals based on a realistic assessment of facts. This was confirmed in a study by
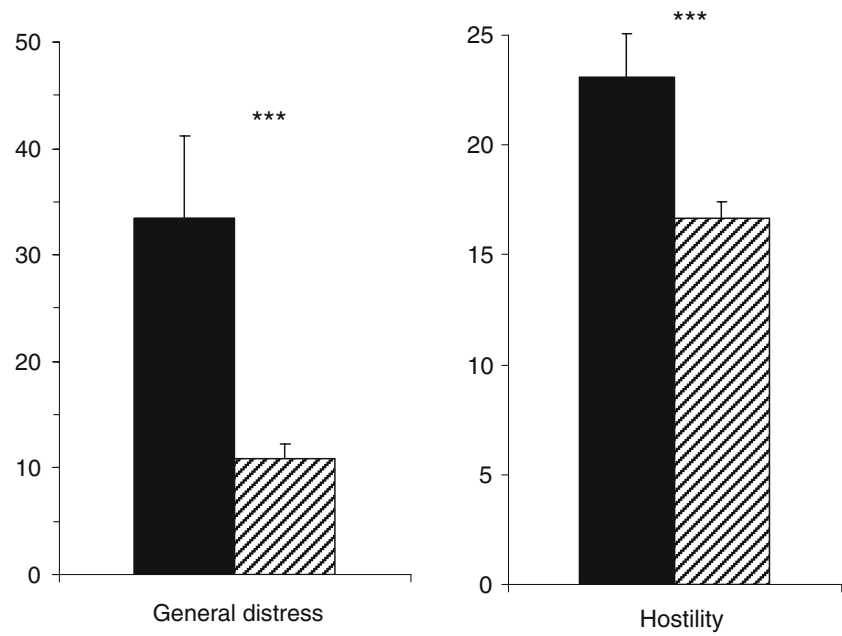

Fig. 2 Differences in general distress and hostility for Type D (black) versus non-Type D (striped) military personnel. Left SCL-90 total score psychoneuroticism, right Cook-Medley hostility score. $*^{* *} p<.001$. Mean + SEM are shown 
Schiffer et al. [31] showing that Type D persons were less likely to seek help for chronic heart failure symptoms despite appraising their complaints as worrisome. A high score on negative effect, and consequently Type D personality, suggests that this group is more at risk for worrying after a traumatic event but at the same time may be less likely to seek help.

Compared to the non-Type D group, the Type D group shows harm avoidance levels in the range of the general population, but even within the low harm avoidance range, the relationship between being low in harm avoidance and at the same time being less shy and passive becomes apparent. Therefore, the Type D group may be considered to benefit less from the protective effect of a harm avoidance score compared to their non-type D colleagues. The TCI-105 scores of the other subscales showed that nonType D military persons had significantly higher levels of novelty seeking (being curious, easily bored, and impulsive) and persistence (perseverant, ambitious) and lower scores in reward dependence (independence), cooperativeness (hostility, aggressive), and self-transcendence (rational, controlling) than the general population. This finding was confirmed in the study of Rademaker and colleagues [32] for all scales except the reward dependence and cooperativeness scales. The temperament and character subscales of the Type D subgroup were not different from the general population, with two exceptions: Type D persons had significantly lower scores for reward dependence and cooperativeness, as compared to the general population. On the extreme end, low reward dependence is associated with being socially insensitive and indecisive, and persons low in cooperativeness tend to be inconsiderate of other people's rights or feelings. How and if these traits show a pre-existing vulnerability for combat-related health problems is not known to date.

Hostility, psychoneuroticism, negativism, and predeployment PTSD symptoms are risk factors for future development of deployment-related health complaints [16, 19, 33-35]. The group with Type D personality showed the highest levels of health-related complaints such as PTSD symptoms, general level of distress, and hostility. The combination of high scores on negative affect and social inhibition may, therefore, render the Type D persons least protected, compared to the non-Type D group, for future development of deployment related health complaints. In a group of Polish firefighters, Type D personality was related to PTSD symptoms [36]. Moreover, the suggestion that Type D persons are more prone to pessimistic worrying, but less likely to seeking help, adds to this vulnerability.

A limitation of this study is the relatively small number of participants in the Type D subgroup. Any statistical problems due to nonlinearity, however, were exploratively examined by nonparametric analysis, which did not yield different results. We have included young, healthy male military personnel who participated on a voluntary basis; this may have introduced a bias, and as a result, the generalizability of these findings may remain limited to similar (military) samples. The cross-sectional design is a limitation as well; we can only speculate on the effect of Type D personality on possible long-term health outcomes. Longitudinal research on deployment-related health problems is, therefore, indispensable.

Despite these shortcomings, the results show that Type D personality is a promising pre-existing risk factor for poor health outcome. The multi-trait approach, observing temperament and character scales, general distress and known risk factors as hostility and PTSD symptoms in relation to the Type D construct, all support the potential role of Type D personality as a risk factor.

In conclusion, both Type $\mathrm{D}$ subscales negative affectivity and social inhibition were related to more harm avoidance (temperament) and less self-directedness (character) in young, healthy men. This suggests that men with a Type D personality have a tendency to be more at risk for worrying after a traumatic event but at the same time may be less likely to seek help. Despite good overall mental health in this group of men awaiting deployment, those with a Type D personality showed the highest levels of PTSD symptoms, general emotional distress, and hostility. We, therefore, speculate that persons with Type D personality are the most vulnerable to post-deployment health complaints, which may prove its value as a predictor in follow-up studies.

Acknowledgements This study is part of a larger study on prospective research in stress-related military operations (PRISMO) and is subsidized by a grant from the Ministry of Defense of the Netherlands. The authors are greatly indebted to Col C. IJzerman, MD and the commanders and troops for their time and effort. The present research was also supported in part by VICI Grant (\# 453-04-004) from the Netherlands Organization for Scientific Research to Dr. Johan Denollet.

Open Access This article is distributed under the terms of the Creative Commons Attribution Noncommercial License which permits any noncommercial use, distribution, and reproduction in any medium, provided the original author(s) and source are credited.

\section{References}

1. Denollet J. DS14: standard assessment of negative affectivity, social inhibition, and Type D personality. Psychosom Med. 2005;67:89-97.

2. Pedersen SS, Denollet J. Is Type D personality here to stay? Emerging evidence across cardiovascular disease patient groups. Curr Cardiol Rev. 2006;2:205-13.

3. Pedersen SS, Denollet J. Validity of the Type D personality construct in Danish post-MI patients and healthy controls. J Psychosom Res. 2004;57:265-72. 
4. Steptoe A, Molloy GJ. Personality and heart disease. Heart. 2007;93:783-4.

5. De Fruyt F, Denollet J. Type D Personality: A Five-Factor Model Perspective. Psychol Health. 2002;17:671-83.

6. Cloninger CR, Svrakic DM, Przybeck TR. A psychobiological model of temperament and character. Arch Gen Psychiatry. 1993;50:975-90.

7. De Fruyt F, De Wiele L-V, Van Heeringen C. Cloninger's psychobiological model of temperament and character and the Five-Factor Model of personality. Pers Individ Differ. 2000;29:441-52.

8. Engelhard IM, Van Den Hout MA, Weerts J, Arntz A, Hox JJCM, McNally RJ. Deployment-related stress and trauma in Dutch soldiers returning from Iraq: Prospective study. $\mathrm{Br} \mathrm{J}$ Psychiatry. 2007;191:140-5.

9. Boscarino JA. Posttraumatic Stress Disorder and Physical Illness: Results from Clinical and Epidemiologic Studies. Ann NY Acad Sci. 2004;1032:141-53.

10. Hoge CW, Castro CA, Messer SC, McGurk D, Cotting DI, Koffman RL. Combat duty in Iraq and Afghanistan, mental health problems, and barriers to care. N Engl J Med. 2004;351:13-22.

11. Mehlum L, Koldsland BO, Loeb ME. Risk factors for long-term posttraumatic stress reactions in unarmed UN military observers: a four-year follow-up study. J Nerv Ment Dis. 2006;194:800-4.

12. Schnurr PP, Spiro 3rd A. Combat exposure, posttraumatic stress disorder symptoms, and health behaviors as predictors of selfreported physical health in older veterans. J Nerv Ment Dis. 1999;187:353-9.

13. Stein AL, Tran GQ, Lund LM, Haji U, Dashevsky BA, Baker DG. Correlates for posttraumatic stress disorder in Gulf War veterans: a retrospective study of main and moderating effects. J Anxiety Disord. 2005;19:861.

14. Sareen J, Cox BJ, Afifi TO, Stein MB, Belik SL, Meadows G, et al. Combat and peacekeeping operations in relation to prevalence of mental disorders and perceived need for mental health care: findings from a large representative sample of military personnel. Arch Gen Psychiatry. 2007;64:843-52.

15. Milliken CS, Auchterlonie JL, Hoge CW. Longitudinal assessment of mental health problems among active and reserve component soldiers returning from the Iraq war. JAMA. 2007;298:2141-8.

16. Bramsen I, Dirkzwager AJ, van der Ploeg HM. Predeployment personality traits and exposure to trauma as predictors of posttraumatic stress symptoms: a prospective study of former peacekeepers. Am J Psychiatry. 2000;157:1115-9.

17. Cox BJ, MacPherson PSR, Enns MW, McWilliams LA. Neuroticism and self-criticism associated with posttraumatic stress disorder in a nationally representative sample. Behav Res Ther. 2004:42:105.

18. Gil S, Caspi Y. Personality Traits, Coping Style, and Perceived Threat as Predictors of Posttraumatic Stress Disorder After Exposure to a Terrorist Attack: A Prospective Study. Psychosom Med. 2006;68:904-9.

19. Heinrichs M, Wagner D, Schoch W, Soravia LM, Hellhammer DH, Ehlert U. Predicting posttraumatic stress symptoms from pretraumatic risk factors: a 2-year prospective follow-up study in firefighters. Am J Psychiatry. 2005;162:2276-86.

20. Duijsens IJ, Spinhoven P, Goekoop JG, Spermon T, EurelingsBontekoe EHM. The Dutch temperament and character inventory
(TCI): dimensional structure, reliability and validity in a normal and psychiatric outpatient sample. Pers Individ Dif. 2000;28:487-99.

21. Duijsens IJ, Spinhoven P, Verschuur M, Eurelings-Bontekoe LHM. De ontwikkeling van de Nederlandse verkorte temperament en karakter vragenlijst (TCI-105) [The development of the Dutch short-form of the temperament and character inventory (TCI105)]. Ned Tijdschr Psychol. 1999;54:276-83.

22. Hovens JE, Bramsen I, van der Ploeg HM. Self-rating inventory for posttraumatic stress disorder: review of the psychometric properties of a new brief Dutch screening instrument. Percept Mot Skills. 2002;94:996-1008.

23. van Zelst WH, de Beurs E, Beekman AT, Deeg DJ, Bramsen I, van Dyck R. Criterion validity of the self-rating inventory for posttraumatic stress disorder (SRIP) in the community of older adults. J Affect Disord. 2003;76:229-35.

24. Arrindel WA, Ettema JHM. Dimensionele structuur, betrouwbaarheid en validiteit van de Nederlandse bewerking van de Symptom Checklist (SCL-90). Dimensional structure, reliability and validity of the Dutch translation of the Symptom Checklist (SCL-90). Lisse: Swets \& Zeitlingero; 1981. Document Number.

25. Arrindell WA, Ettema JHM. SCL-90: herziene handleiding bij een multidimensionele psychopathologie indicator. SCL-90: a revised manual for a multidimensional psychopathology indicator. Lisse: Swets \& Zeitlingero; 2003. Document Number.

26. Barefoot JC, Dodge KA, Peterson BL, Dahlstrom WG, Williams Jr RB. The Cook-Medley hostility scale: item content and ability to predict survival. Psychosom Med. 1989;51:46-57.

27. Suarez EC, Lewis JG, Krishnan RR, Young KH. Enhanced expression of cytokines and chemokines by blood monocytes to in vitro lipopolysaccharide stimulation are associated with hostility and severity of depressive symptoms in healthy women. Psychoneuroendocrinology. 2004;29:1119.

28. Tabachnick BG, Fidell LS. Using multivariate statistics. 5th ed. Boston: Pearson; 2007.

29. Hotopf M, Hull L, Fear NT, Browne T, Horn O, Iversen A, et al. The health of UK military personnel who deployed to the 2003 Iraq war: a cohort study. Lancet. 2006;367:1731-41.

30. Cloninger CR, Bayon C, Svrakic DM. Measurement of temperament and character in mood disorders: a model of fundamental states as personality types. J Affect Disord. 1998;51:21-32.

31. Schiffer AA, Denollet J, Widdershoven JW, Hendriks EH, Smith OR. Failure to consult for symptoms of heart failure in patients with a type-D personality. Heart. 2007;93:814-8.

32. Rademaker AR, Vermetten E, Geuze E, Muilwijk A, Kleber RJ. Self-reported early trauma as a predictor of adult personality: a study in a military sample. J Clin Psychol. 2008;64:863-75.

33. Orth U, Wieland E. Anger, hostility, and posttraumatic stress disorder in trauma-exposed adults: a meta-analysis. J Consult Clin Psychol. 2006;74:698-706.

34. Ouimette P, Cronkite R, Prins A, Moos RH. Posttraumatic stress disorder, anger and hostility, and physical health status. J Nerv Ment Dis. 2004;192:563-6.

35. Rona RJ, Hooper R, Jones M, Hull L, Browne T, Horn O, et al. Mental health screening in armed forces before the Iraq war and prevention of subsequent psychological morbidity: follow-up study. BMJ. 2006;333:991.

36. Ogińiska-Bulik N, Langer I. Type D personality, coping with stress and intensity of PTSD symptoms in firefighters. Med Pr. 2007;58:307-16. 